\title{
Comparison of physical fitness of rural, semi-urban and urban of primary school children in their abdominal strength, flexibility and cardio-respiratory endurance in federal capital territory, Nigeria
}

\begin{abstract}
Introduction: Physical fitness is the ability to perform moderate to vigorous levels of physical activity without undue fatigue, having ample energy to enjoy leisure time pursuits and to meet unforeseen emergencies.
\end{abstract}

\begin{abstract}
Aim: This study was conducted to compare the physical fitness performance levels among rural, semi-urban and urban of primary school children in their abdominal strength, flexibility and cardio-respiratory endurance in Federal Capital Territory, Abuja, Nigeria.
\end{abstract}

Methods: To achieve this purpose, a total of 270 subjects were used in this research They were randomly selected from among the schools, to serve as subjects in the study. All the subjects were tested in the selected variables e.g. flexibility, muscular endurance and cardio-respiratory.

Results: The results of the findings of this study did not revealed significant difference between the male and female subjects involved in the test. The results further revealed no significant difference between gender and between subjects from the rural, urban and semi-urban schools in their cardio-respiratory endurance. The findings of this study also revealed that subjects did not differ significantly by gender in their flexibility performance. However, the flexibility performance of semi-urban school subjects in the Federal Capital Territory is significantly different from that of the rural and urban school subjects. There was no significant difference between subjects in rural and urban schools in their flexibility, whereas the subjects in rural, semiurban and urban schools did not differ significantly in their cardio-vascular endurance measured by the $\mathrm{VO}_{2 m}$

Conclusion: The results of study confirmed that between the male and female subjects in the rural, semi-urban and urban primary schools in the Federal Capital Territory, irrespective of their locations, did not differ significantly in their abdominal strength, flexibility and cardio-vascular endurance measured.

Recommendation: On the basis of the results of this study, it was recommended that facilities and equipment for physical education activities should be provided by the stakeholders in primary schools of the Federal Capital Territory, Abuja.

Keywords: cardio-respiratory endurance, physical fitness, flexibility, urban primary school, semi urban primary school
Volume 2 Issue I - 2018

\author{
Suleiman UO,' Eze ED, ${ }^{2}$ Tsauri YM,' Adewale \\ JB,' Abdullahi Y,' Olasunkanmi OU, ${ }^{3}$ Adams \\ $\mathrm{MD}^{4}$ \\ 'Department of Physical and Health Education, Ahmadu Bello \\ University, Nigeria \\ ${ }^{2}$ Department of Physiology, Kampala International University, \\ Ugand \\ ${ }^{3}$ Nigeria Army Physical Training School, Nigeria \\ ${ }^{4}$ Department of Biochemistry, Bingham University, Nigeria
}

Correspondence: Eze Ejike Daniel, Department of Physiology, Faculty of Biomedical Sciences, Kampala International University, Uganda,Tel 256782975042, Email daniel.ejike@kiu.ac.ug

Received: January 15, 2017 | Published: February 08, 2018

\section{Introduction}

Physical fitness has been described as the ability to perform moderate to vigorous levels of physical activity without undue fatigue yet having ample energy to enjoy leisure time pursuits to meet unforeseen emergencies. Most frequently cited components of physical fitness are those related to health and those related to athletic skills. The skill related components are important for various individuals and team sports task of athletes for competitive performances. ${ }^{2}$ It has been proven that individuals, who engage in regular physical activity to develop cardiovascular and optimal body fat level, appear to enjoy improved basic energy level and fitness. ${ }^{3}$ It therefore means that deliberate programmes must be put in place that would provide the Nigerian child with knowledge; attitude, motor skills behavior and confidence to participate in physical activity that will make him/her live active life in schools and community that contribute to improve fitness status throughout adult life. ${ }^{4}$ In most developed countries of the world, different fitness tests are often carried out for all subpopulation groups for decision on fitness and health status. Commonly assessed fitness statuses are aerobic fitness: batteries as strength, endurance, flexibility and body composition of children, adolescents and adults. The focus of each test is to evaluate functional activities in the population sub-group. Aerobic fitness is the ability of the heart, lungs and blood vessels to supply oxygen to the working muscles and the ability of the muscles to use the available oxygen for continuous exercise. ${ }^{5}$ Aerobic fitness can be influenced by the life style patterns of children which can be modeled by the school Physical Education programmes. Excess body fat is found to lower aerobic fitness, 
endurance and strength in children and adolescents. It also reduces children's ability to perform many activities like running, jumping and lifting of weights. ${ }^{5}$ Suitable body composition is important for general health, appearance and for enhancing performance in sport and fitness evaluation. Fitness can be measured by the volume of oxygen you can consume while exercising at your maximum capacity. $\mathrm{VO}_{2 \max }$ is the maximum amount of oxygen in milliliters, one can use in one minute per kilogram of body weight. Those who are fit have higher $\mathrm{VO}_{2 \max }$ values and can exercise more intensely than those who are not as well conditioned. Numerous studies show that you can increase your $\mathrm{VO}_{2}$ max by working out at an intensity that raises your heart rate to between 65 and $85 \%$ of its maximum for at least 20 minutes three to five times a week. The delivery of oxygen to active tissues that is the major limiting factor to $\mathrm{VO}_{2 \max }{ }^{6}$ There is now substantial research evidence indicating that physical activity during adulthood produces a number of major health benefits. A consensus committee concluded that physical activity is associated with a reduction in allcause mortality, fatal and non-fatal total cardiovascular disease, and a reduction in the incidence of obesity, Type 2 diabetes mellitus, colon cancer and osteoporosis. ${ }^{7}$ Recent reviews also indicated that physical activity can have beneficial effects on young people's psychological well-being, self-esteem, over weight and obesity, and chronic disease risk factors. The most consistent association seems to exist between physical activity and body fatness. ${ }^{8}$ The role of physical activity on the reduction of obesity is becoming of increasing importance, as obesity has emerged as the most common paediatric chronic illness in western countries. ${ }^{9}$ Despite the evidence linking physical activity with health, sustained periods of moderate to vigorous physical activity are not characteristic of young people's physical activity patterns. ${ }^{10}$ And activity levels seem to decline after the age of 12. Nevertheless, more recent evidence seems to suggest that young people may be more active when cumulative activity and less stringent intensity thresholds are considered..$^{11}$ The present study was aimed at assessing the comparison of physical fitness of rural, semi-urban and urban of primary school children in their abdominal strength, flexibility and cardio-respiratory endurance in Federal Capital Territory, Abuja, Nigeria.

\section{Methodology}

For the purpose of this study, the research design adopted was the exposit factor research design as suggested by. ${ }^{12}$ There were eight hundred and ninety six thousand pupils in the primary schools of FCT, Abuja. A stratified random sampling technique was used in this study. With this technique, FCT was divided into three settlements rural, semi-urban and urban centers. From each stratum, three 3 primary schools were selected at random by dip and pick method. In each of the 3 schools selected, the schools attendance registers was used to select the subject's base on gender. 30 respondents ( 15 boys and 15 girls) were sampled each, culminating to two hundred and seventy (270) respondents that were used as the sample size for the study.

\section{Tests}

The following tests batteries were used to assess the selected physical fitness of the subjects:
a. Sit and reach for flexibility
b. Sit-ups for Abdominal Strenght
c. 12-minute Run/walk test for $\mathrm{VO}_{2 \max }$

\section{Height and weight}

The standard anthropometric protocol of the International Working Group on Kinanthropometry (IWGK) described by ${ }^{13}$ was used to measure height and weight. The height was taken in meters and the weight in kilograms, using the Laboratory weighing scale (Shemond) with subjects dressed in a minimum sportswear and without shoes. The body mass index was determined by dividing the weight $(\mathrm{kg})$ by the square of height $(\mathrm{m})$.

$$
B M I=\left(\mathrm{kg} / \mathrm{m}^{2}\right)
$$

BMI: Body Mass Index; Kg: Kilograms; M: Meters

\section{Sequence of testing}

To avoid fatigue on the subjects, the tests were conducted in the following order:
a. Sit ups
b. Sit and reach
c. 12 minutes run

\section{Sit-up}

This is to test the subjects' abdominal strenght. The equipment used for this test was: mats, whistle and a stop watch. Each subject was allowed a minute trial thereafter she/he repeated the test twice and the average computed for each subject.

Procedure: The subjects lied on their back with fingers clasped behind the neck and elbows touching the floor with the knee bent, and the toes flat on the ground. The upper body was pulled close to the bent knees. The ankle was held firm to the ground by an assistant. The subject continued to repeat the exercise for 60 seconds.

Scoring: A good sit-up was scored each time the elbow touched the knee. The scores were the number of correct sit- ups performed within 60 seconds, while each research assistant scored each subject.

\section{Sit and reach}

The sit and reach test was used for the hip flexion of the subjects as described by ${ }^{14-16}$ The apparatus consisted of a box (constructed) with a measuring scale of $23 \mathrm{~cm}$ at the level of the feet. The box was placed against the wall. The subjects removed their shoes and assumed a sitting position on the floor with legs fully extended forward with the hands placed on top of each other. In this position, the subject stretched forward, the maximum reach on each trial with the knees fully extended and the feet still in contact with the box. The distance attained was recorded to the nearest $\mathrm{cm}$. For each trial, the maximum distance reached and maintained for ten seconds was a measure of the subject's flexibility.

\section{I2-Minutes run/walk test}

This test is used to determine the subject's cardio-respiratory endurance.

Procedure: The subjects were required to run/walk around the $400 \mathrm{me}-$ ters track as many times as possible within the 12 minute period. The subjects were to run/walk at their own pace. Each of the subjects may walk or stop completely when tired. To avoid biased, subjects were 
randomly selected, 12 per group to run, while the research assistant helped to count the number of laps covered by each subject. At the expiration of the 12 minutes, whistle was blown and all the subjects stopped and remained at their points until the research assistant went around marking the distance each of the subjects had covered.

\section{Experimental controls}

To avoid any form of external influence on the result of the test, the following measures were taken into consideration:

A. All the subjects were advised not to get involved in any physical activity a day before the test to avoid fatigue or stress before the test.

B. All the subjects were advised not to eat at least four hours before the test to avoid nauseating effect on their stomach.

C. The testers were rotated on the tests at random to avoid being bias for any test.
D. All the tests were conducted under the same conditions within the school environment.

\section{Results}

Two hundred and seventy subjects made up of 90 each from urban, semi-urban and rural areas of the Federal Capital Territory were selected for the study. To eliminate any bias associated with gender, equal number of males and females (45 each) were selected in each location making 45 male and female from the primary school in each location. A summary of the descriptive statistics of age, weight, height, of the subject is presented in Table1. Table 1 reveals that the mean and standard deviation values of the rural, semi-urban and urban subjects did not vary very much in terms of their age, weight, height, waist hip ratio (WHR) and their BMI. However, this generalization also varies for dimensions of the selected parameters among the male and female subjects from the different locations. Table 2(A) gives the descriptive statistics of the investigated variables used in the analysis of the research questions and the study's hypotheses.

Table I Demographic characteristics of the subjects in their Age, Weight, Height, body mass index (BMI) and waist hip ratio (WHR)

\begin{tabular}{llllllll}
\hline Variables & Sex & Rural & \multicolumn{3}{c}{ Semi-urban } & Urban \\
\cline { 3 - 8 } & & Mean & SD & Mean & SD & Mean & SD \\
\hline Age $(\mathrm{yr})$ & Male & 10.88 & 0.804 & 10.93 & 0.828 & $1 \mathrm{I} . \mathrm{II}$ & 0.804 \\
& Female & $1 \mathrm{I} .02$ & 0.833 & 10.8 & 0.761 & 10.82 & 0.806 \\
Weight $(\mathrm{kg})$ & Male & 35.23 & 7.087 & 36.67 & 7.869 & 31.41 & 6.603 \\
& Female & 35.3 & 5.717 & 34.62 & 5.988 & 35.78 & 7.844 \\
Height $(\mathrm{m})$ & Male & 1.33 & 0.072 & 1.27 & 0.098 & 1.29 & 0.107 \\
& Female & 1.32 & 0.08 & 1.35 & 0.101 & 1.29 & 0.101 \\
BMI $(\mathrm{kg} / \mathrm{m} 2)$ & Male & 20.19 & 4.608 & 22.94 & 5.751 & 19.37 & 5.363 \\
& Female & 20.5 & 4.198 & 19.27 & 5.034 & 21.97 & 6.437 \\
WHR & Male & 0.86 & 0.056 & 0.85 & 0.043 & 0.84 & 0.045 \\
& Female & 0.84 & 0.054 & 0.85 & 0.053 & 0.85 & 0.041 \\
\hline
\end{tabular}

SD, Standard Deviation

Table 2(A) Mean scores of the subject by sex and locations of the schools in abdominal strength performances

\begin{tabular}{lllll}
\hline \multirow{2}{*}{ Location } & Male & \multicolumn{3}{c}{ Female } \\
\cline { 2 - 5 } & Mean & SD & Mean & SD \\
\hline Rural & 1.82 & 0.382 & 1.74 & 0.261 \\
Semi urban & 1.71 & 0.347 & 1.8 & 0.359 \\
Urban & 1.72 & 0.28 & 1.75 & 0.284 \\
Total & 1.76 & 0.345 & 1.76 & 0.291 \\
\hline
\end{tabular}

\section{Hypotheses testing}

The major hypothesis of the study is aimed at determining the statistical differences in the physical fitness of rural, semi-urban and urban primary schools children of the Federal Capital Territory, Abuja. The major hypothesis was devolved into two null sub-hypotheses for the selected physical fitness variables for purpose of establishing statistical significance of the findings.
Sub-hypotheses I: There is no significant difference between rural, semi-urban and urban of primary school children in FCT Nigeria in their abdominal strength test. The hypothesis was tested with the two way analysis of variance because of the inclusion of the subjects' sex and location of the subjects. The mean scores of the subjects by sex and the location of their schools is presented in Table 2(A).

The mean scores of the subjects by sex and locations in abdominal strength showed the male and female pupils had mean and SD scores of $1.82 \pm 0.38$ and $1.74 \pm 0.26$ respectively. Those in the Semi- Urban had $1.71 \pm 0.35$ and $1.80 \pm 0.36$ respectively. The subjects in the Urban had $1.72 \pm 0.280$ and $1.75 \pm 0.29$ respectively. To test if statistical differences exist in their performance score, the data has being analyzed in ANOVA and the results presented in Table 2(B).

The result in the table did not reveal significant difference between the male and female subjects involved in the test $(\mathrm{P}>0.05)$. In the same vein, the subjects did not differ significantly in their muscular strength by their different locations $(\mathrm{P}>0.05)$. The interaction between the subject sex and the location of their school did not show any significant difference. Therefore, the null hypothesis which states 
that there is no significant difference between rural, semi-urban and urban of primary school children in FCT, Nigeria in their muscular strength test is therefore retained.

Table 2(B) Analysis of variance on abdominal strength test by location and sex of subjects

\begin{tabular}{lllll}
\hline Source & $\begin{array}{l}\text { Sum of } \\
\text { squares }\end{array}$ & Df & $\begin{array}{l}\text { Mean } \\
\text { square }\end{array}$ & F \\
\hline Corrected Model & 0.429 & 5 & 0.086 & 0.843 \\
Sex & 0.012 & 1 & 0.012 & 0.122 \\
Location & 0.097 & 2 & 0.049 & 0.477 \\
Sex* location & 0.33 & 2 & 0.165 & 1.624 \\
Error & 26.842 & 264 & 0.102 & \\
Total & 865.666 & 270 & & \\
Corrected Total & 27.271 & 269 & & \\
\hline
\end{tabular}

$F(I, 264)=3.89, P>0.05 \quad F(2,264)=3.04, P<0.05$

DF, Degree of Freedom; F, F-Statistic

Sub-hypothesis II: There is no significant difference between rural, semi-urban and urban primary school children in FCT, Abuja in their flexibility test. One way variance (ANOVA) procedure using the generalized linear model was used for the determination of the significance difference between the subjects consisting of the male and female in the three locations. Their performances on flexibility test were used as the dependent variable in the test. The mean scores by the male and female subjects on the flexibility test by their different locations are presented in Table 3(A).

Table 3(A) Mean scores of the subjects' performances in flexibility by their locations

\begin{tabular}{lllll}
\hline \multirow{2}{*}{ Location } & Male & \multicolumn{3}{l}{ Female } \\
\cline { 2 - 5 } & Mean & SD & Mean & SD \\
\hline Rural & 21.27 & 5.09 & 19.89 & 3.068 \\
Semi-urban & 23.21 & 4.99 & 23.13 & 5.04 \\
Urban & 21.79 & 4.09 & 22.55 & 4.619 \\
Total & 21.88 & 4.78 & 21.5 & 4.333 \\
\hline
\end{tabular}

The means shown in the table revealed that the performance in flexibility of the subjects from semi-urban schools had the highest score of 23.17. This score by semi-urban subjects cut across male and female. The least score was obtained from subjects in the rural schools. The female from rural schools were particularly low in their score (19.89) and was the least score among the subjects in the three locations.

The result of the analysis of variance model for the hypothesis is summarized in Table 3(B).

There was no significant difference in the flexibility performance between the male and female subjects in the flexibility test $(\mathrm{P}>0.05)$. But the subjects differed significantly in their flexibility performance by the different locations $(\mathrm{P}<0.05)$. The interaction of the subjects' sex by their respective locations did not revealed significant difference in the test $(\mathrm{P}>0.05)$. From this observation, the main thrust of the null hypothesis which is identification of difference in flexibility by location is completely addressed and was found to be positive $(\mathrm{P}<0.05)$. The null hypothesis that there is no significant difference between rural, semi-urban and urban children of FCT Abuja in their flexibility is therefore rejected. The subjects differ significantly by their locations in flexibility mean scores. The post hoc test performed on the overall mean scores by location of the subjects using the Scheffe procedure is summarized in Table 3(C).

Table 3(B) Analysis of variance (ANOVA) on flexibility by male and female subjects in the three locations

\begin{tabular}{llllll}
\hline Source & $\begin{array}{l}\text { Sum of } \\
\text { squares }\end{array}$ & Df & $\begin{array}{l}\text { Mean } \\
\text { square }\end{array}$ & F & Sig. \\
\hline Corrected Model & 370.985 & 5 & 74.197 & 3.753 & 0.003 \\
Sex & 3.464 & 1 & 3.464 & $0.175^{*}$ & 0.676 \\
Location & 300.793 & 2 & 150.4 & $7.607^{* *}$ & 0.001 \\
Sex* location & 60.407 & 2 & 30.203 & $1.528^{*}$ & 0.219 \\
Error & $5,219.22$ & 264 & 19.77 & & \\
Corrected Total & $5,590.21$ & 269 & & & \\
\hline
\end{tabular}

Table 3(C) Result of Scheffe test on the mean scores of the subjects by their locations

\begin{tabular}{lllll}
\hline (I) Location & (J) Location & $\begin{array}{l}\text { Mean } \\
\text { difference }(I-J)\end{array}$ & Std. error & Sig. \\
\hline Rural & Semi urban & $-2.5936\left(^{*}\right)$ & 0.70303 & $.00 I^{*}$ \\
& Urban & $-1.5917\left(^{*}\right)$ & 0.62001 & 0.039 \\
\multirow{2}{*}{ Semi urban } & Rural & $2.5936\left(^{*}\right)$ & 0.70303 & $.00 I^{*}$ \\
& Urban & 1.0019 & 0.74105 & 0.402 \\
\multirow{2}{*}{ Urban } & Rural & $1.5917\left(^{*}\right)$ & 0.62001 & $.039^{*}$ \\
& Semi urban & -1.0019 & 0.74105 & 0.402 \\
\hline
\end{tabular}

*The mean difference is significant at the .05 level

The result revealed that the observed significant difference in the flexibility of the subjects was between the rural and semi-urban on one hand and rural and urban on the other. Between the semi-urban and urban subjects no significant difference was observed in their flexibility performance.

Sub-hypotheses III: There was no significant difference between rural, semi-urban and urban children in FCT Abuja in their cardiorespiratory endurance test. The scores of the subjects in their $\mathrm{VO}_{2}$ max as accessed by 12-minutes run/walk tests was used to test this hypothesis by sex and locations of the subjects. The mean scores of the subjects in $\mathrm{VO}_{2}$ max by the locations of the subjects have been presented in Table 4(A).

Though variability in the mean scores was not found to be statistically significant but subjects from the rural schools have relatively higher mean performance score of 4.412 in the cardiorespiratory endurance test and were followed by subjects from urban schools with a mean score of 36.03 . Subjects from semi-urban schools had the least score of $35.42 \pm 3.814$. To test if these mean scores were statistically significant, analysis of variance was computed and the result is presented in Table 4(B). 
Table 4(A) Mean scores of the subject by sex and locations in $\mathrm{VO}_{2}$ max

\begin{tabular}{lllll}
\hline \multirow{2}{*}{ Location } & Male & \multicolumn{3}{c}{ Female } \\
\cline { 2 - 5 } & Mean & SD & Mean & SD \\
\hline Rural & 36.64 & 4.41 & 35.42 & 3.814 \\
Semi urban & 34.7 & 3.34 & 35.25 & 4.321 \\
Urban & 35.45 & 5.21 & 34.69 & 4.199 \\
Total & 35.81 & 4.53 & 35.14 & 4.043
\end{tabular}

The variability observed between the male and female subjects was not found to be statistically significant $(\mathrm{P}>0.05)$. Across the different locations, the test did not reveal significant differences in the cardiorespiratory endurance test of the subjects $(\mathrm{P}>0.05)$. The interaction of the sex of the subjects and their location was also not found to be statistically significant $(\mathrm{P}>0.05)$. Therefore, the null hypothesis which states that there is no significant difference between rural, semi-urban and urban primary school children in FCT, Abuja in their cardiorespiratory endurance is therefore accepted.

Table 4(B) Analysis of variance on cardio-respiratory endurance test by location and sex of subjects

\begin{tabular}{llllll}
\hline Source & Sum of squares & Df & Mean square & F & Sig. \\
\hline Corrected Model & 129.713 & 5 & 25.943 & $1.415^{*}$ & 0.219 \\
Sex & 14.356 & $\mathrm{I}$ & 14.356 & $0.783^{*}$ & 0.377 \\
Location & 66.856 & 2 & 33.428 & $1.823^{*}$ & 0.164 \\
Sex* location & 31.869 & 2 & 15.934 & $0.869 *$ & 0.421 \\
Error & $4,840.92$ & 264 & 18.337 & & \\
Corrected Total & $4,970.64$ & 269 & & & \\
\hline
\end{tabular}

\section{$F(I, 264)=3.89, P>0.05$}

\section{Discussion}

$F(2,264)=3.04, P<0.05$

This study compared the physical fitness of children in urban, semi-urban and rural schools in the Federal Capital Territory, Abuja. The fitness variables were abdominal strength, flexibility and cardiorespiratory endurance. Sub-hypothesis I abdominal strength, the result did not reveal significant difference between the male and female subjects involved in the test, the subjects did not differ significantly in their abdominal strength by their different locations. The interaction between the subject sex and the location of their school did not show any significant difference. Therefore, the null hypothesis which states that there is no significant difference between rural, semi-urban and urban of primary school children in FCT, Nigeria in their abdominal strength test is therefore retained. The result of this test is consistent with the report of, ${ }^{2}$ carried out a Comparison of Health Related Physical Fitness Components between Urban and Rural Primary School Children in India. The study investigated the comparison of health related physical fitness components between urban and rural primary school children. The sample was 20 subjects, 9 years of age 10 of urban primary school children (girls) and 10 subjects of rural primary school children (girls). Five Health related physical fitness components (40 yard dash, standing broad jump, handgrip, sit and reach and 600 yard run/walk) were taken. The result shows that the static strength of rural children was significantly higher than the urban school children. But there is no significant difference of speed, explosive strength, flexibility and cardiovascular endurance components between urban and rural primary school children.

Sub-hypothesis II test for significant differences in flexibility. The results of the fitness test on flexibility of urban, semi-urban and rural subjects revealed no significant difference by gender. However, significant different was observed between the subjects by the location of schools. The null hypothesis was therefore rejected. From the post hoc test revealed that the subjects from rural schools performed better in flexibility than those in semi - urban and urban schools. However, no difference in performance was observed between the semi-urban and urban subjects in their flexibility performances.
* Not significant

The results of this test is consistent with the report of ${ }^{17}$ study, conducted on Greek rural and urban students to find out whether those living in urban or rural settings differ from those in the rural areas in their flexibility test. The study revealed that pupils in urban areas were better off than those in the rural areas. A similar result was obtained in the work of ${ }^{18}$ who conducted a study on physical fitness in rural children compared with urban children in Turkey and found that children living in the urban areas were more inactive and obese than rural children. The result of this present study tended to be in line except that the urban is here splinted. The point here is that subjects in semi-urban schools tended to have better opportunities for exposure and freedom to participate in exercises and thus increase their flexibility with the assistance of available facilities and equipment which may not be available to subjects in the rural schools. For the urban schools, restriction imposed by privatization of schools thereby limiting space and the associated sports facilities and equipment could be a constraining factor.

Sub-hypothesis III test for significant differences in the $\mathrm{VO}_{2}$ (Volume Oxygen) maximum oxygen consumption during incremental exercise between the rural, semi-urban and urban school subjects. The result of the analysis of variance used for the test did not reveal significant difference between the male and the female and between subjects from the rural, urban and semi-urban schools. This hypothesis was therefore accepted. The finding here agrees with, ${ }^{2}$ study of Comparison of Health Related Physical Fitness Components between Urban and Rural Primary School Children in India. The study did not find significant difference in the speed, explosive strength, flexibility and cardiovascular endurance components between urban and rural primary school children.

The finding from this present study is however contrary to the finding of ${ }^{19}$ study conducted on the estimation of maximum oxygen uptake $\left(\mathrm{VO}_{2 \max }\right)$ by evaluating cooper 12-min run test in female students of West Bengal, India. In the report, it was observed that rural female young students do have a statistical significantly higher value of predicted maximum aerobic capacity $\left(\mathrm{VO}_{2 \max }\right)$ than the 
urban female young students with a probability of $\mathrm{P}<0.001$. The study concluded that the rural female students have a higher cardio respiratory fitness due to significantly high $\mathrm{VO}_{2 \max }$ value in $12 \mathrm{~min}$ run Cooper test. This present study did not find significant difference between the rural, semi-urban and urban subjects. The male and female subjects involved did not differ significantly in their cardiorespiratory endurance.

\section{Conclusion}

I. The results of the study confirm that there is a significant difference in the physical fitness performances of rural, semi-urban and urban primary schools in the FCT, Abuja.

II. Physical fitness variables where such significant differences existed among the subjects in the three locations are flexibility.

III. The subjects in the rural, semi-urban and urban primary schools in the Federal Capital Territory did not differ significantly in their abdominal strength.

IV. The subjects in the rural, semi-urban and urban primary schools in the Federal Capital Territory did not differ significantly in their cardio-vascular endurance measured with Vo2 max.

\section{Recommendations}

Based on the findings from the analyzed data, the researcher would want to recommend as follows:

I. Facilities and equipment for physical education activities should be provided by the stakeholders of primary schools in the rural locations of the Federal Capital Territory, Abuja.

II. Provision of adequate space for recreational activities should be one of the basic requirements for the establishment of primary schools in the urban areas of the Federal Capital Territory.

III. Part of the mandatory inspectorial requirement during school inspection should include sports facilities and equipment for primary school pupils in the Territory.

IV. There is need for professional recruitment of physical Education Teachers in the schools who have the rudimentary knowledge of physical and recreational activities for primary school children in all the schools in urban rural and semi-urban schools.

\section{Acknowledgements}

None.

\section{Conflict of interest}

Author declares that there is no conflict of interest.

\section{References}

1. AAHPERD. American Alliance for Health, physical Education, Recreation and Dance. Health Related Fitness Test Manual, USA; 2001.
2. Singh TR, Kanchan. Comparison of Health Related Physical Fitness Components between Urban and Rural Primary School Children. VSRDIJBMR. 2012;2(5):187-192.

3. World Health Organisation. Global Database of Body mass index (BMI). WHO, USA; 2006.

4. Suleiman UO. Comparative study of the physical fitness of the Nigerian Army, Airforceand Navy personnel. MSc thesis, Exercise and Sports Science Unpublished. Ahmadu Bello University, Nigeria; 2008.

5. Andrew C Fry. Overtraining with Resistance Exercise. American College of Sports Medicine. Annual Review of Public Health.2001;8:212-220.

6. French J, Long M. How to improve your $\mathrm{VO}_{2} \max$. Athletics Weekly, UK; 2012. p. 53.

7. Facchini F, Fiori G, Bedogni G, et al. Prevalence of overweight and cardiovascular risk factors in rural and urban children from Central Asia: The Kazakhstan Health and Nutrition examination survey. Am J Hum Biol. 2007;19(6):809-820.

8. Kelishadi R. Childhood overweight, obesity and the metabolic syndrome in developing countries. Epidemiol Rev. 2007;29:62-76.

9. Mayo MJ, Grantham JR, Balasekaran G. Exercise-induced weight loss preferentially reduces abdominal fat. Med Sci Sports Exerc. 2003;35(2):207-213

10. Simonen JA, Smoll FL. An instrument for assessing children's attitudes toward physical activity. Research Quarterly. 2013;45(4):407-415.

11. Astrand PO. Active Lifestyle in childhood and youth can prevent adult diseases. Journal of Applied Physiology. 1996;75:311-316.

12. Thomas JR, Nelson JK. Research Methods in Physical Activity. Human Kinetics, USA; 1996. p. 496.

13. Ross WD, Jones MJ. Kinanthropometry. In: Doughal SD, et al. editor Physiological Test of Elite Athletes Motoal publishing Ohawa, Canada; 1992.

14. Mathew DK. Measurement in Physical Education, 5th ed. WB Saunders Company, USA; 1978. p. 495.

15. Corbin CB. Flexibility. Clin Sports Med. 1984;3(1):101-117.

16. Dikki CE. Validation of the vertical Toes: Sit and Research Measurement of Lumber Flexibility. Sports Science and Medicine. 1992;1:2-6.

17. Tsimeas PD, Tsiokanos AL, Koutedakis Y, et al. Does living in urban or rural settings affect aspects of physical fitness in children? Br J Sports Med. 2005;39(9):671-674.

18. Ozdirenç M, Ozcan A, Akin F, et al. Physical fitness in rural children compared with urban children in Turkey. Pediatr Int. 2005;47(1):26-31.

19. Banibrata D. Estimation of maximum oxygen uptake by evaluating cooper 12 min run tests in female students of west Bengal, India. Journal of Human Sport and Exercise. 2013;8(4):1008-1014. 